\title{
Development and validation of venlafaxine hydrochloride in bulk and in capsule formulation by HPTLC
}

\begin{abstract}
A simple, sensitive and rapid high performance thin layer chromatographic (HPTLC) method has been developed and validated for quantitative estimation of Venlafaxine hydrochloride in bulk and in capsule formulation. The drug was chromatographed on silica gel 60F254TLC plate using methanol: ammonia (4.5:0.5v/v) as mobile phase. Densitometric scanning of was carried out at $224 \mathrm{~nm}$ and resolution was found with Rf value $0.65 \pm 0.02$. The linear regression analysis for the calibration plots showed good linear relationship with $\square 2=0.998$ in concentration range $500-3000 \mathrm{ng} / \mathrm{spot}$. The minimum detectable amount was found to be $7.7 \mathrm{ng} / \mathrm{spot}$, whereas the limit of quantitation was found to be $23.3 \mathrm{ng} / \mathrm{spot}$. The method was validated for precision, recovery, repeatability and robustness as per the ICH guidelines. Statistical analysis of the data showed that the method is precise, accurate, reliable, reproducible, and selective for the analysis of Venlafaxine hydrochloride. The proposed method also indicates no interference of excipients from capsule formulation.
\end{abstract}

Volume 4 Issue 3 - 2017

\author{
Vivekkumar K Redasani, Priyanka R Patel, \\ Sanjay J Surana \\ Department of Pharmaceutical Chemistry, India
}

Correspondence: Vivekkumar K Redasani, Department of Pharmaceutical Chemistry, R.C. Patel Institute of Pharmaceutical Education and Research, Shirpur, Dhule (MS), India, Tel 9.19822E+I I, Email vivek.redasani@gmail.com

Received: January 31, 2017 | Published: March 17, 2017

Keywords: high performance thin layer chromatography, venlafaxine hcl, validation, ich guidelines, precision, recovery, repeatability, robustness, concentration, statistical analysis, precise, accurate, reliable, reproducible, quantitative

\section{Introduction}

Venlafaxine hydrochloride (VEN; Figure 1) is serotonin or epinephrine reuptake inhibitor (SNRI) class to be used clinically as antidepressant. ${ }^{1,2}$ Chemically it is (R/S)-1-[2- (dimethylamino) -1-(4-methoxyphenyl) ethyl] cyclohexanol hydrochloride..$^{2-4}$ It works by blocking the transporter "reuptake" proteins for key neurotransmitters affecting mood, thereby leaving more active neurotransmitters in the synapse. ${ }^{5,6}$ It has a simultaneous effect on noradrenaline reuptake and some weak effects on dopamine reuptake. The combination of the effects on the reuptake mechanisms appears to be responsible for the antidepressant action of the drug. ${ }^{7,8}$

Chromatographic estimation of Venlafaxine $\mathrm{HCl}$ was reported by using few HPLC methods either in combination or individual in pharmaceutical dosage form. ${ }^{9-12}$ In the same context a method for estimation by HPTLC was also available as reported to study the degradation kinetics ${ }^{13}$ and also HPTLC analysis of Venlafaxine hydrochloride in the bulk drug and tablets. ${ }^{14}$

Based on the available literature sources, it was thought that there is scope for development of simplified HPTLC method for VEN. Even though some methods of analysis are available but it was thought to perform the estimation by more sophisticated technique. Therefore; the present study illustrates the development and validation of simple, sensitive and rapid HPTLC method for estimation of VEN in bulk and in capsule dosage form. The proposed method is optimized and validated according to ICH guidelines.

\section{Materials and methods}

\section{Instrumentation and chemicals}

The HPTLC system (Camag, Muttenz, Switzerland) equipped with a sample applicator Linomat $\mathrm{V}$ connected to a nitrogen cylinder, twin trough plate development chamber $(10 \times 10 \mathrm{~cm})$, TLC Camag Scanner III and Wincats 4.02. Pre-coated silica gel 60 F254 TLC aluminium plates $(0.2 \mathrm{~mm}$ thick) were obtained from E. Merck Ltd., Mumbai
(India); Densitometric analysis was carried out using TLC scanner III winCATS software.

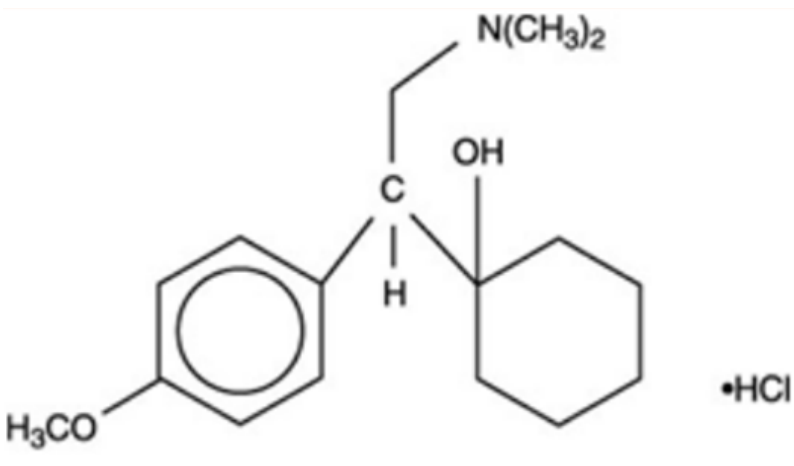

\section{venlafaxine hydrochloride}

Figure I Chemical structure of Venlafaxine hydrochloride.

Venlafaxine hydrochloride was kindly supplied as a gift sample by Zydus Pharmaceuticals Ltd., India. Methanol and ammonia employed were of analytical grade and used as solvents to prepare the mobile phase. Capsule formulation Veniz XR (Sun Pharmaceuticals Ltd., India) was used as pharmaceutical preparation for analysis.

\section{Method}

\section{Standard stock solution preparation}

An accurately weighed $10 \mathrm{mg}$ of drug was transferred to $10 \mathrm{~mL}$ volumetric flask; dissolved in methanol and the volume was made upto the mark with same solvent to obtain working standard of $1000 \mathrm{ng} / \mu 1$.

\section{Optimization of mobile phase and chromatographic conditions}

On the basis of polarity, ethyl acetate was selected as trail solvent for mobile phase. It was followed by further trials by combining 
with methanol in varying ratios. The developed spot was diffused and tailing was observed. To the above mobile phase, $1 \mathrm{~mL}$ methanol was added. The peak was found to be symmetrical in nature with tailing hence; ammonia was added to remove tailing effect. Finally, the mobile phase methanol: ammonia $(4.5: 0.5 \mathrm{v} / \mathrm{v})$ gave good, sharp and symmetrical peak with Rf value of 0.65 for VEN. Plates were developed to a distance of $8 \mathrm{~cm}$ in Camag twin-trough glass chamber previously saturated with mobile phase vapors for $25 \mathrm{~min}$ at ambient temperature. Densitometric scanning was performed at $22 \mathrm{~nm}$. A typical chromatogram of VEN in bulk showing $\mathrm{Rf}$ value 0.65 is shown in Figure 2.

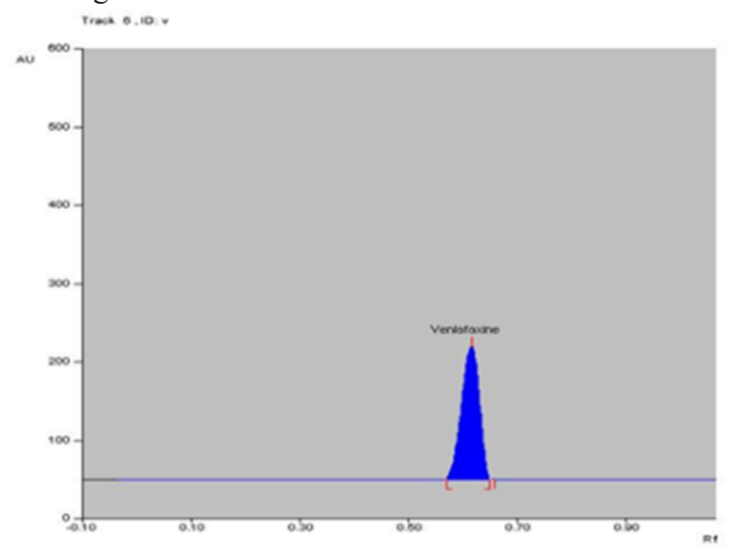

Figure 2 Chromatogram of standard Venlafaxine $\mathrm{HCl}$ showing $\mathrm{Rf}$ value 0.65 .

\section{Validation of proposed method}

The proposed method was validated across the various parameters like linearity, accuracy, precision, sensitivity, reproducibility, repeatability and robustness studies as per the ICH guidelines. ${ }^{15}$ System suitability test of the chromatography system was performed before each validation run.

\section{Linearity}

Linearity was performed using working standard of VEN. Calibration was done by applying standard stock solution ranging from $0.5-3.0 \mu \mathrm{L}$ on TLC Plate; which gives concentration of 500 $3000 \mathrm{ng} / \mathrm{band}$. The plate was developed and scanned as described under chromatographic conditions.

\section{Bulk assay}

Bulk assay was assessed by six replicates determinations covering the specified range for the procedure viz; $1500 \mathrm{ng} / \mathrm{band}$ of VEN on a TLC plate followed by development and scanning as described above.

\section{Accuracy}

Recovery experiment was assessed at three different concentrations ( $80 \%, 100 \%$ and $120 \%$ concentration). To the pre-analyzed sample solutions (1500ng/band), a known amount of drug standard solution of VEN was over applied in triplicate and analyzed. This procedure was repeated for three consecutive days. Calibration curves to estimate the concentration of drug per spot were measured daily on the same plates as the samples. The accuracy was determined and expressed as percentage recovery.

\section{Precision}

Precision of the method was studied as repeatability and intraday and inter-day variations. Intra-day and Inter-day variation was assessed at three different concentrations 500, 1000 and 1500ng of drug solutions. Intra-day assay precision was found by analysis of standard drug at three times on the same day. Inter-day assay precision was carried out using at three different days and percentage relative standard deviation (\%RSD) was calculated.

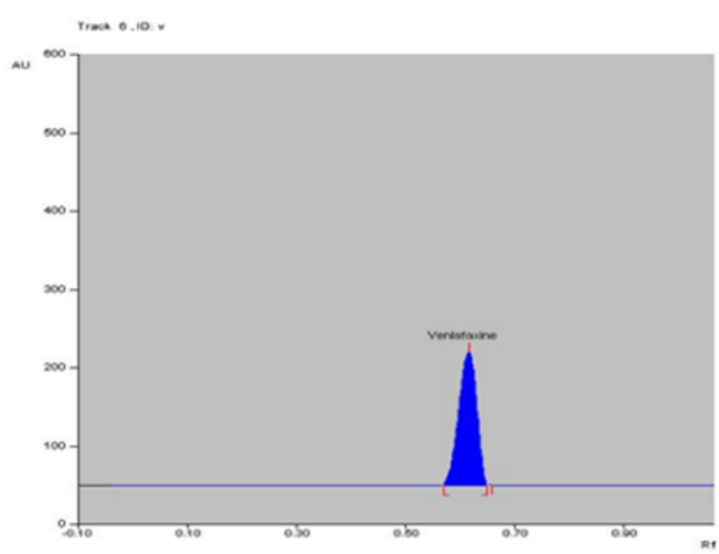

Figure 3 Calibration curve plot for Venlafaxine $\mathrm{HCl}$.

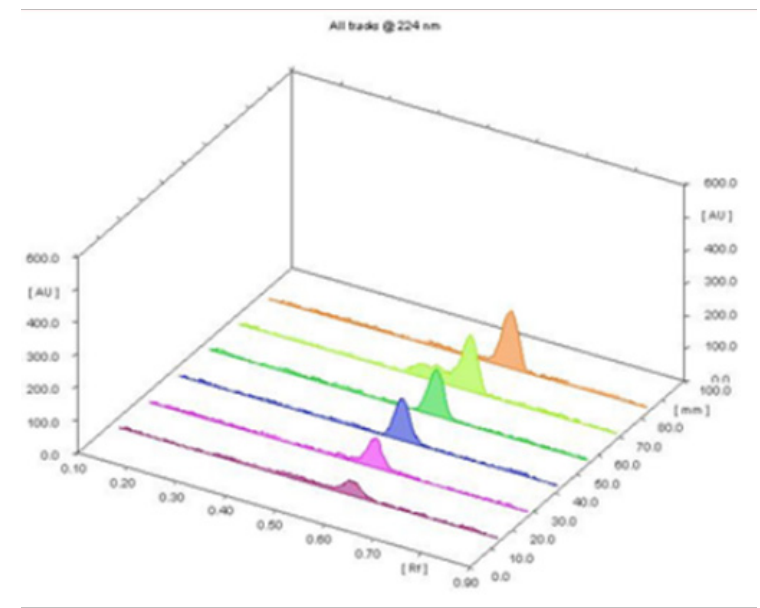

Figure 4 3D Chromatogram of Venlafaxine $\mathrm{HCl}$.

\section{Sensitivity}

Sensitivity of the proposed method was estimated in terms of limit of detection (LOD) and limit of quantitation (LOD). The LOD and LOQ were calculated by the use of the equation $\mathrm{LOD}=3.3 \times \mathrm{N} / \mathrm{B}$ and $\mathrm{LOQ}=10 \times \mathrm{N} / \mathrm{B}$; where, ' $\mathrm{N}$ ' is standard deviation of the peak areas of the drugs $(n=3)$, taken as a measure of noise, and ' $B$ ' is the slope of the corresponding calibration curve. Different volumes of stock solution in the range $500-1000 \mathrm{ng} / \mathrm{band}$ were applied on HPTLC plate in triplicate.

\section{Repeatability}

It is measured by multiple injections of a homogenous sample of $1500 \mathrm{ng} / \mathrm{band}$ of VEN that indicates the performance of the HPTLC instrument under chromatographic conditions followed by development of plate and recording the peak height and area for six bands.

\section{Robustness}

By introducing small but deliberate changes in the mobile phase composition, mobile phase volume and duration of mobile phase saturation, the effects on the results were examined. 
Table I Recovery study

\begin{tabular}{|c|c|c|c|c|c|}
\hline$\%$ level & Initial Amount (ng/band) & Amount Added (ng/band) & Amount found $\pm S D$ (ng/band) $(n=3)$ & \% Recovery & \% RSD \\
\hline 80 & 1500 & 1200 & $2690.4 \pm 13.1$ & 99.64 & 0.48 \\
\hline 100 & 1500 & 1500 & $2997.8 \pm 3.54$ & 99.92 & 0.11 \\
\hline 120 & 1500 & 1800 & $3322.5 \pm 13.3$ & 100.68 & 0.4 \\
\hline
\end{tabular}

Table 2 Data of precision study

\begin{tabular}{|c|c|c|c|c|}
\hline \multirow[t]{2}{*}{ Conc. (ng/band) } & \multicolumn{2}{|c|}{$\begin{array}{l}\text { Intra day } \\
\text { amount found (ng/band) }\end{array}$} & \multicolumn{2}{|c|}{$\begin{array}{l}\text { Inter day } \\
\text { amount found (ng/band) }\end{array}$} \\
\hline & Mean士SD & $\% \operatorname{RSD}(n=3)$ & Mean士S.D. & $\% \operatorname{RSD}(n=3)$ \\
\hline 500 & $446.3 I \pm 2.4 I$ & 0.16 & $443.98 \pm 2.65$ & 0.18 \\
\hline 1000 & $959.99 \pm 3.89$ & 0.15 & $959.16 \pm 4.26$ & 0.17 \\
\hline 1500 & $1519.95 \pm 18.56$ & 0.51 & $1510.97 \pm 32.7$ & 0.92 \\
\hline
\end{tabular}

Table 3 Results of Robustness Study

\begin{tabular}{lll}
\hline Parameters & $\mathbf{\pm}$ SD of peak area $(\mathbf{n}=\mathbf{3})$ & \% RSD \\
\hline Mobile phase composition $(A \mathrm{mmonia}, \pm 0.5 \mathrm{~mL})$ & 8.09 & 0.32 \\
Development distance $( \pm 0.5 \mathrm{~cm})$ & 35.9 & 1.68 \\
Duration of saturation $( \pm 5 \mathrm{~min})$ & 30.8 & 1.09
\end{tabular}

\section{Formulation assay}

To determine the content of VLN in pharmaceutical dosage form, Contents of twenty capsules were crushed to make a uniform powder having label claim of $37.5 \mathrm{mg}$. A quantity of powder which is equivalent to $37.5 \mathrm{mg}$ of VEN was weighed accurately and transferred into a $10 \mathrm{ml}$ calibrated volumetric flask; finally the volume was adjusted to the mark. The resulting solution obtained was then filtered, through $0.45 \mu \mathrm{m}$ filter for complete removal of particulate matter. $5 \mathrm{ml}$ of the filtrate was diluted to $25 \mathrm{ml}$ in the volumetric flask with the diluent for analysis. A single spot at Rf 0.61 was observed in the chromatogram of the drug samples extracted from conventional capsules. There was no interference from the excipients commonly present in the conventional capsules. The drug content was found to be $100.9 \%$ with a $\%$ R.S.D. of less than $2 v i z ; 1.01$. The low $\%$ R.S.D. value indicated the suitability of this method for routine analysis of VEN in pharmaceutical dosage forms.

\section{Results and discussion}

An HPTLC/densitometric method has been developed successfully for the determination of Venlafaxine hydrochloride in bulk and in capsule formulation. The estimation of drug was performed on precoated silica gel $60 \mathrm{~F} 254 \mathrm{TLC}$ aluminium plates $(0.2 \mathrm{~mm}$ thick) using methanol: ammonia $(4.5: 0.5 \mathrm{v} / \mathrm{v})$ as mobile phase. The densitometric quantification for the drug was carried out at $224 \mathrm{~nm}$. The Rf value for VEN was found to be 0.65 .

The proposed method has been validated for various parameters like linearity, accuracy, precision, sensitivity, reproducibility, repeatability and robustness as per ICH guidelines. The calibration curve obtained by plotting peak area against concentration showed linearity in the concentration range of 500-3000ng/ $\mu 1$ per band and calibration curve constructed to be $\mathrm{r} 2=0.998$. The bulk assay for Venlafaxine hydrochloride was performed and the amount found is close to $100 \%$ when area was calculated for $1500 \mathrm{ng} / \mathrm{spot}$ and six determinations. Calibration curve was constructed by plotting the peak area $v s$. corresponding drug concentration as shown in Figure 3 and 3-D linearity chromatogram is shown in Figure 4.

The proposed method was applied for pharmaceutical capsule formulation and \% label claim for VEN was found to be $100.98 \%$.
As the retention time of VEN in bulk solution was same as marketed formulation solution and also there was no interference found of excipients. The mean recovery obtained for VEN was $99.64-100.68 \%$ and $\%$ RSD found was 1.7. The accuracy data tabulated in Table 1 show that the method is accurate within desired range.

The precision results expressed as \%RSD and were found to be less than 2 for both intra-day and inter-day precision. There was no significant difference in the \%RSD values, which indicates that the proposed method is precise. The detail results are tabulated in Table 2.

The LOD and LOQ for VEN were found to be 7.7ng and 23.3ng respectively. The values were low which indicates that the method is sensitive and no interference of the excipients with the peaks of interest appeared. It indicates the specificity of the method for quantitative estimation of drug in marketed formulation. The robustness of an analytical procedure is a measure of its capacity to remain unaffected by small, but deliberate variations in method parameters, and provides an indication of its reliability during normal usage. Robustness of the method was done in triplicate at a concentration level of $1000 \mathrm{ng} /$ spot and the \% RSD peak area was calculated and shown in Table 3. Hence, the proposed method is applicable for the routine estimation of VEN in pharmaceutical dosage form.

\section{Conclusion}

The reported HPTLC method was proved to be simple, rapid, and reproducible. The validation data indicate sensitivity, precision, accuracy, and reliability of the method for estimation of Venlafaxine $\mathrm{HCl}$ in bulk and capsule dosage form. The method was successfully validated as per ICH guidelines. The method is reproducible, sensitive, economical and simple for estimation of drug in bulk and marketed formulation without any excipients interference.

\section{Acknowledgements}

The authors are thankful to Zydus Pharmaceutical Ltd., Ahmadabad, Gujarat (India) for providing gift sample of Venlafaxine hydrochloride.

\section{Conflicts of Interest}

The authors do not have any personal or financial interests. 


\section{Funding}

None.

\section{References}

1. Ellingrod VL, Perry PJ. Venlafaxine: a heterocyclic antidepressant. Am J Hosp Pharm. 1994;51(24):3033-3046.

2. Rossby SP, Manier DH, Liang S, et al. The serotonin/norepinephrine-link in brain. II. The International Journal of Neuropsychopharmacology. 1999;2:1-8.

3. Holliday SM, Benfield P. Venlafaxine. A review of its pharmacology and therapeutic potential in depression. Drugs. 1995;49(2):280-294.

4. Maj J, Rogoz Z. Pharmacological effects of venlafaxine, a new antidepressant, given repeatedly, on the $\alpha 1$-adrenergic, dopamine and serotonin systems. Journal of neural transmission. 1999;106(2):197211.

5. Schreiber S, Bleich A, Pick CG. Venlafaxine and Mirtazapine. Journal of Molecular Neuroscience. 2002;18(1):143-149.

6. Davis JL, Smith RL. Painful peripheral diabetic neuropathy treated with venlafaxine $\mathrm{HCl}$ extended release capsules. Diabetes Care. 1999;22(11):1909-1910.

7. Ereshefsky L. Drug-Drug Interactions Involving Antidepressants: Focus on Venlafaxine. J Clin Psychopharmacol. 1996;16(3):37S-50S.
8. Kiayias JA, Vlachou ED, Lakka-Papadodima E, et al. Venlafaxine $\mathrm{HCl}$ in the treatment of painful peripheral diabetic neuropathy. Diabetes Care. 2000;23(5):699.

9. Peikova L, Pencheva I, Maslarska V. Development of HPLC method for determination of Venlafaxine during concomitant use of metoprolol. Pharmacia. 2013;60: 12-16.

10. Edla S. A novel RP-HPLC method for the determination of Venlafaxine in pharmaceutical drug products. Int J sci Tech. 2012;1:11-21.

11. Rao B, Kiran B, Dubey S. Validation of Venlafaxine in pharmaceutical dosage by Reverse Phase HPLC. J Pharm Res. 2012;5(5):2683-2687.

12. Kang H, Kang M, Jin H, et al. Development of a LC-MS/MS for quantification of Venlafaxine in human plasma and application to bioequivalence study in healthy korean subjects. TCP. 2004;22(1):3542.

13. Ramesh B, Narayan PS, Reddy AS, et al. Stability-indicating HPTLC method for analysis of venlafaxine hydrochloride, and use of the method to study degradation kinetics. Journal of Planar Chromatography. 2011;24(2):160-165.

14. Shirvi C, Suhagia B, Shah N, et al. HPTLC analysis of venlafaxine hydrochloride in bulk drug and tablets. Journal of Planar Chromatography. 2010;23(5):251-255.

15. ICH. Validation of Analytical Procedures: Text and Methodology. International Conference on Harmonization. Geneva, USA. 2005;p. $1-13$. 